\title{
Markseheiderisehes Übungsbuch
}

\section{für Studierende des Bergfaches und für Bergreferendare}

\section{Gehrke}

Oberbergamtsmarkscheider

und Dozent an der Bergakademie Clausthal

\section{Mit 9 Figuren}

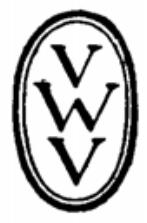

Berlin und Leipzig 1920

Vereinigung wissenschaftlicher Verleger Walter de Gruyter \& Co. 
Alle Rechte, insbesondere das Übersetzungsrecht, von der Verlagshandlung vorbehalten. 